\title{
O IMPACTO DOS INVESTIMENTOS EM P\&D NO RETORNO DAS AÇÕES: UM ESTUDO DAS COMPANHIAS DE ENERGIA ELÉTRICA LISTADAS NA B3 ${ }^{1}$
}

\section{THE IMPACT OF RED INVESTMENTS ON STOCK RETURN: A STUDY OF THE ELECTRIC POWER COMPANIES LISTED ON B3}

\author{
Maria Lucrécia Jorge Izidoro \\ Graduada em Ciências Contábeis (Universidade Federal de Uberlândia - UFU) \\ lucrecia.izidoro@gmail.com \\ Josilene da Silva Barbosa \\ Doutora em Ciências Contábeis (Universidade Federal de Uberlândia - UFU) \\ Professora da Universidade Federal de Uberlândia (UFU) \\ josilene@ufu.br \\ Kelly Aparecida Silva Jacques \\ Doutoranda em Ciências Contábeis (Universidade Federal de Uberlândia - UFU) \\ kelly asilva@yahoo.com.br

\section{Thiago Alberto dos Reis Prado} \\ Doutor em Controladoria e Contabilidade (Universidade de São Paulo - USP) \\ Professor da Universidade Federal de Uberlândia (UFU) \\ thiagoalberto@ufu.br
}

\section{RESUMO}

Objetivo: Verificar se o investimento em P\&D resulta em Value Relevance para o mercado de capitais das empresas do setor de energia elétrica listadas na B3.

Fundamento: Em virtude de um cenário global marcado pela competição, e da importância do setor elétrico para a economia, a Pesquisa e Desenvolvimento (P\&D) é uma ferramenta eficaz às entidades por promover o aperfeiçoamento e a inovação, cada vez mais requeridos pelos consumidores e necessários às empresas.

Método: A análise dos dados foi realizada para o período de 2010 a 2018, utilizando-se de regressão múltipla com os dados em painel, por meio do Software Stata 13.

Resultados: Os resultados apontam que os investimentos em P\&D realizados por essas entidades geram conteúdo informacional relevante para influenciar o valor de mercado das empresas. Os achados demonstram que demora pelo menos três anos para os gastos em P\&D gerarem um efeito positivo no retorno das ações.

\footnotetext{
${ }^{1}$ Artigo recebido em: 04/03/2020. Revisado por pares em: 15/04/2020. Reformulado em: 16/05/2020. Recomendado para publicação: 22/04/2020 por Anna Paola Fernandes Freire (Editora Adjunta). Publicado em: 25/05/2020. Organização responsável pelo periódico: UFPB
} 
Contribuições: Os resultados podem ser de interesse a empresas ou setores da economia que buscam realizar investimento em $P \& D$, e também contribui com a literatura dado que há divergências em estudos anteriores ao relacionar o investimento em P\&D e o retorno das ações.

Palavras-chave: Pesquisa e Desenvolvimento. Setor de energia elétrica. Investimento.

\section{ABSTRACT}

Objective: To verify whether investment in R\&D results in Value Relevance for the capital market of companies in the electric power sector, listed in B3.

Rationale: Due to a global competitive scenery, and the importance of the electricity sector for the economy, Research and Development (R\&D) is an effective tool for entities, as it promotes improvement and innovation, which are increasingly required by consumers and necessary for companies.

Method: Data analysis took place from 2010 to 2018, using multiple regression with panel data using Stata Software 13.

Results: The results show that the investments in R\&D made by these entities generate relevant informational content to influence the companies' market value. The findings demonstrate that it takes at least three years for spending on $R \& D$ to generate a positive effect on stock returns.

Contributions: the results may be of interest to companies or sectors of the economy that seek to make investments in $P \& D$ and also contribute to a literature that diverges in previous studies related to investments or investments in P\&D and stock return.

keywords: Research and Development. Electricity sector. Investment.

\section{INTRODUÇÃO}

O avanço tecnológico sugere às empresas que sejam empreendidos esforços em Pesquisa e Desenvolvimento - P\&D a fim de que estejam aptas a acompanhar o cenário de transformações globais. Andreassi e Sbragia (2002) consideram a P\&D protagonista nesse contexto competitivo que busca a excelência, em razão da dependência das organizações em oferecer portfólio atraente, melhor custo benefício, atributo superior e agilidade em relação à concorrência.

O Manual Frascati (2015) define a Pesquisa e Desenvolvimento como uma atividade criativa que contribui para a ampliação do conhecimento do homem, da cultura e da sociedade em prol da criação de novas aplicações. Para que seja considerada como P\&D, a atividade deve satisfazer os requisitos básicos, tais como ser inovadora, criativa, incerta, sistemática, transferível e/ou reprodutível. Ou seja, uma atividade de processo organizado, a qual dá origem a um produto e/ou processo novo, que tenha sua aplicabilidade viável.

Embora alguns estudos tenham sido realizados com o propósito de discutir a importância da P\&D para as empresas, ainda não há consenso acerca do impacto dos investimentos nos seus resultados. Chan, Lakonishok e Sougiannis (1990) encontraram uma relação positiva entre investimento em P\&D e o preço das ações em empresas de alta tecnologia. Foi evidenciado também que, mesmo quando as empresas apresentam redução nos lucros, os investimentos em P\&D afetam positivamente o preço das ações. Mais tarde, Chan, Lakonishok e Sougiannis (2001), para a análise da relevância, constataram que não houve diferença significativa no preço das ações em empresas que realizam a P\&D e aquelas que não realizam esse investimento. Hungarato e Teixeira (2012), encontraram que os gastos com P\&D foram considerados insignificantes para o preço das ações em empresas de baixo a elevado nível tecnológico. É válido destacar que os trabalhos de Chan et al (1990) e Chan et al (2001) foram realizados em empresas norte-americanas submetidas ao padrão contábil Generally Accepted Accounting Principles (US GAAP), enquanto o estudo de Hungarato e 
Teixeira (2012) foi realizado com empresas brasileiras subordinadas às normas International Financial Reporting Standards (IFRS).

Para a concepção dos benefícios frente à concorrência, é essencial que a pesquisa e desenvolvimento sejam coerentes com o planejamento estratégico da entidade (Lima \& Sauaia, 2008). Em busca de inovação, bem como para resistir aos desafios tecnológicos e de mercado do setor de energia elétrica, a Agência Nacional de Energia Elétrica - ANEEL, por meio do Manual do Programa de Pesquisa e Desenvolvimento Tecnológico do Setor de Energia Elétrica, e em atendimento à Lei no 9.991/2000, estabeleceu que as empresas do setor devem prever a aplicabilidade anual de um valor mínimo de investimento em P\&D. Esse investimento deve apresentar resultados práticos, uma vez que são estabelecidas metas e previsão de resultados, além de o projeto desenvolvido ter que demonstrar originalidade e inovação.

Os esforços por parte da ANEEL em promover a pesquisa e desenvolvimento nas companhias por ela regulamentadas tem como propósito produzir novos equipamentos, além de aperfeiçoamento dos serviços, para uma maior segurança e redução dos impactos ambientais, bem como contribuir para a independência tecnológica do país.

Em razão disso, foi realizada uma análise dos dados das companhias de energia elétrica listadas na B3 - Brasil, Bolsa, Balcão, no período de 2010 a 2018, com o intuito de responder o seguinte questionamento: Qual a relação entre os gastos com pesquisa e desenvolvimento e o retorno das ações?

Tendo em vista que Galdi, Teixeira e Lopes (2008) consideram o preço das ações como uma interação de vários fatores que formam a expectativa do mercado sobre o desenvolvimento futuro de uma empresa, tal verificação consiste em identificar se o investimento em $P \& D$ agrega valor à entidade, tendo em vista que a continuidade das organizações está atrelada à capacidade de inovar e promover constantemente o avanço, optando por mecanismos que proporcionarão maior qualidade e rendimentos (Berto \& Dias Junior, 2015). Rodrigues, Elias e Campos (2015) destacam que a expansão do mercado financeiro, bem como a ampliação do vínculo entre os mercados foram responsáveis por desencadear a elaboração de informações indispensáveis que aprimoram o processo decisório e a tomada de decisão. Para o CPC 00 (2011), a informação contábil-financeira que tem a capacidade de influenciar a tomada de decisão dos usuários é extremamente relevante.

Suadiye (2012) descreve o value relevance como o atributo da informação contábil que capta e sintetiza o valor da empresa por meio de associações estatísticas realizadas entre as informações divulgadas e o valor de mercado das ações. Para Hungarato e Teixeira (2012), entender o quão expressivo o investimento em P\&D é para o preço das ações beneficiará a tomada de decisões e elaboração do planejamento das entidades, ao fornecer informações relevantes para sustentar as escolhas dos gestores. Chan et al (2001) consideram que a P\&D se associa ao preço das ações pela percepção dos investidores em admitir que ativos intangíveis, tais como pesquisa e desenvolvimento, agregam valor a entidade.

A presente pesquisa se justifica pelo conteúdo informacional apresentado, o qual poderá ser de interesse para outras empresas ou setores da economia interessados em realizar investimento em $\mathrm{P} \& \mathrm{D}$, bem como pelas divergências encontradas em estudos anteriores ao relacionar o investimento em P\&D e o preço das ações. O estudo é importante também por analisar um modelo de negócio no qual existe a obrigatoriedade de se investir em P\&D. Além disso, em razão de a amostra compreender um período de 9 anos após promulgação da Lei no 9.991/2000, que trata da imposição em realizar tal investimento por parte das companhias elétricas, será possível verificar se esse investimento passou a agregar valor à entidade após esse período, visto que, no estudo de Alves, Silva, Macedo e Marques (2011), foi analisado o setor de energia elétrica no período de 2002 a 2009, ou seja, logo após a lei prever a obrigatoriedade de realizar a P\&D. 
A próxima seção deste artigo apresenta aspectos sobre a relevância do investimento em $P \& D$ para as organizações empresariais em busca de elucidar algumas consequências da realização ou não desses investimentos em um cenário global de competitividade.

\section{FUNDAMENTAÇÃO TEÓRICA}

\subsection{Aspectos sobre o Value Relevance da informação contábil}

O comitê de Pronunciamentos Contábeis, em seu pronunciamento conceitual básico - CPC - 00, estabelece que o objetivo das demonstrações contábeis é oferecer informações que tenham utilidade para aqueles que delas usufruirão, com a finalidade de orientá-los na tomada de decisões econômicas e avaliações. E ainda, a utilidade das demonstrações contábeis para seus usuários vai desde fornecer aporte para o tratamento de instrumentos contábeis, para avaliar a entidade quanto a sua capacidade de pagar dívidas, para a determinação de políticas tributárias de distribuição de lucros e dividendos, até a sua utilização para levantamento de dados estatísticos e regulamentação das atividades das empresas.

Silva (2015) salienta que, devido às suas características refinadas, o mercado de capitais requer, gradativamente, informações relevantes para que as oportunidades mais adequadas de investimentos sejam detectadas. O autor destaca ainda que o discernimento dos acionistas pode ser modificado por inúmeras informações e que, nesse mercado, a relevância de uma informação se dá quando o efeito da ciência dessa informação estiver associado ao valor de mercado de uma ação.

As circunstâncias são determinantes para a relevância de uma informação, dependendo do contexto no qual está inserida. Essa relevância advém da possibilidade que a mesma tem de interferir em escolhas (LO, 2010). Para Machado, Macedo e Machado (2015), a variabilidade dos usuários da informação contábil faz com que a relevância seja notada sob panoramas diversos. Por seu turno, as pesquisas de value relevance exploram a relação entre variáveis contábeis e o valor de mercado das organizações.

Barth, Beaver e Landsman(2001) destacam que a literatura interpreta um valor contábil como relevante se esse for capaz de estabelecer uma conexão esperada com o valor de mercado de capital de uma entidade. Quanto à motivação para a realização de pesquisas de value relevance, essa consiste em expandir o conhecimento sobre a relevância e a fidedignidade de valores contábeis e seus reflexos no valor patrimonial das organizações.

Por sua vez, Espíndola, Santos e Vasconcelos (2018) opinam que o estudo sobre value relevance apresenta indícios de que a divulgação de algumas informações, inclusive, das demonstrações contábeis, contribui para a tomada de decisão dos usuários.

Souza e Borba (2017) explanam que a incorporação de variáveis adequadas à divulgação de resultados, além das variáveis de lucro líquido e patrimônio líquido, é relevante para explicar o preço das ações, sendo esse um fator que contribui para amparar a realização de pesquisas de value relevance, a fim de reforçar a importância da divulgação de informações contábeis.

\subsection{Aspectos sobre a relevância da P\&D no contexto empresarial}

Empresas e países atuantes globalmente foram acometidos por uma série de modificações que os compeliram a realizar investimentos com a pretensão de produzir inovação e gerar diferencial competitivo (Lima \& Sauaia, 2008). Andreassi e Sbragia (2002) consideram que P\&D assume notoriedade em função da intervenção que realiza no processo de inovação tecnológica, do qual as entidades se tornaram dependentes, tendo em vista as exigências de um mercado de disputas acirradas que impõe a oferta de produtos de alta qualidade com custo benéfico atraente e com agilidade na oferta.

Berto e Dias Junior (2015) corroboram essa opinião ao destacarem que a continuidade das organizações dependerá da aptidão das mesmas em oferecer produtos de qualidade em um pro- 
cesso de evolução contínua e oriundo da necessidade de adaptação às exigências do mercado. Os autores salientam ainda que muitas empresas se afastam desse propósito ao direcionar seus esforços apenas para a obtenção de lucro mediante redução de custos, sendo o ideal que eles se apoiem em outras ações planejadas, dentre elas, a pesquisa e desenvolvimento.

Outro fator benéfico para as organizações que investirem em P\&D é a possibilidade de aumento do retorno aos acionistas. Alguns investidores são atraídos pelas empresas que investem em P\&D em razão da expectativa de ganhos futuros, o que pode contribuir para o aumento do valor das ações (Chan et al, 2001). Para Rodrigues et al (2015), o conhecimento adquirido em razão da pesquisa e desenvolvimento proporciona às entidades oferecerem produtos ou serviços inovadores, o que facilitará a obtenção dos ganhos em competitividade e retorno aos acionistas, os quais passam a considerar significativa as informações de P\&D fornecidas pelas empresas. Posição semelhante é compartilhada por Espíndola et al (2018), ao considerar que, quando uma organização realiza inovação, decorrente do que foi investido em $P \& D$, pode alterar perspectivas e direcionar escolhas tomadas pelos investidores ao imputar valor às entidades.

O investimento em P\&D é um impulsionador no processo de inovação e constrói modificações que ultrapassam os limites das empresas nas quais ele está inserido. Além de motivar a criação de produtos e processos novos, ele moderniza os parques industriais, contribui para o avanço da alta tecnologia e reafirma a posição de riqueza e desenvolvimento dos países que a ele confere notoriedade (Jensen, Menezes-Filho \& Sbragia, 2004). Santos e Pinheiro (2011) ressaltam que realizar o investimento em P\&D é uma obrigação das empresas para que possam se desenvolver econômica e socialmente, bem como obter vantagens exclusivas no longo prazo.

Umas das razões para o baixo investimento em P\&D por parte das empresas instaladas no Brasil diz respeito a um modelo de industrialização que era praticado no país, tendo como particularidade um robusto protecionismo vinculado a uma economia fechada. Em razão disso, o país encontra-se atrasado em relação às outras economias de mesmo potencial. No entanto, em virtude da abertura de mercado, iniciada ao final da década de 1980, o Brasil pode se beneficiar do investimento estrangeiro que empresas multinacionais têm realizado em P\&D fora de suas sedes, por mirar em produtos mais próximos às condições locais. As empresas multinacionais estimulam a realização de investimentos em P\&D nas empresas nacionais, alçando-as a competir no mercado internacional e contribuindo para uma maior qualificação da mão de obra, uma vez que esse agente é primordial à atividade de pesquisa e desenvolvimento (Queiroz, 2011).

Pires, Dalongaro, Silveira Júnior e Pires (2015) consideram que a organização, ao investir em pesquisa e desenvolvimento, se beneficia da incorporação de valor a sua marca, se aproxima da possibilidade de obter maiores ganhos decorrentes das melhorias de processos e produtos essenciais a uma melhor qualidade de vida, além de assegurar a permanência de seus clientes. Como consequência, tem-se a constituição de companhias sólidas e aptas a encabeçar mercados, utilizar técnicas competitivas e sobressair ao se transformarem em referência de nicho.

Em virtude de todas as especificidades ocasionadas pela integração da economia mundial, as empresas, progressivamente, têm recorrido à $P \& D$ como forma de obter destaque e permanência no mercado. Nessa economia dinâmica e competitiva, na qual os investimentos atuam como precursores de diversos avanços, isso reflete no desenvolvimento econômico e social de empresas e países (Nez, Diel \& Lavarda, 2016).

\subsection{Estudos correlatos sobre P\&D e desenvolvimento de hipóteses}

No trabalho de Andreassi e Sbragia (2002) foram relacionados os indicadores de P\&D com os de resultado empresarial. Como fruto da pesquisa, foi verificado que a intensidade do que é investido em P\&D está extremamente relacionado ao faturamento empresarial, o que é decorrente da elaboração de produtos novos e/ou melhores. Também foi apurado que os investimentos em 
P\&D no Brasil dependem do faturamento da empresa, ou seja, as empresas aguardam o faturamento para decidir sobre o investimento, ao contrário do que ocorre em economias desenvolvidas. Nesse caso, as empresas traçam uma estratégia de longo prazo e invertem-se as variáveis, sendo o faturamento dependente do que foi investido para gerar inovação.

O estudo de Jensen et al (2004) analisa a questão do faturamento e P\&D sob uma ótica inversa, isto é, foi pesquisado pelos autores se a rentabilidade é um fator determinante para que as entidades invistam em P\&D. Como resultado, percebeu-se que as firmas com maior faturamento bruto, mesmo com menor patrimônio líquido, têm maior probabilidade de investir em P\&D. Por outro lado, o lucro não influencia nessa decisão, o que os autores julgaram interessante por considerarem que as flutuações anuais do lucro não devem ocasionar variação do montante a ser investido em P\&D, visto que esse é um investimento de longo prazo.

A relação entre P\&D e índices de rentabilidade foi analisada por Alves et al (2011), os quais estudaram a significância dos gastos com P\&D para o mercado de capitais de empresas de distribuição de energia elétrica. Os resultados demonstraram que o fato de se investir em P\&D é relevante para o mercado de capitais dessas entidades. No entanto, ao relacionar o investimento em P\&D ao lucro líquido e patrimônio líquido, foi averiguado que o investimento em P\&D não produz conteúdo informacional significativo para justificar o valor de mercado dessas empresas do setor elétrico, isto é, o investimento em P\&D não afetou o lucro líquido e tampouco o patrimônio líquido dessas organizações.

A pesquisa de Ferrari (2012) analisou a relação entre folga organizacional e os gastos com Pesquisa e Desenvolvimento com enfoque na fonte de financiamento desse tipo de investimento. Apurou-se que os lucros retidos são a principal fonte para custear os gastos com P\&D, seguidos pelo sistema bancário privado. Os resultados demonstram ainda a disposição das organizações em utilizar recursos próprios e a importância da folga organizacional nesse processo.

No estudo de Hungarato e Teixeira (2012) foi proposto verificar se os gastos com P\&D refletiram no preço das ações de empresas brasileiras listadas na Bovespa. Foi constatado que os investimentos em P\&D não apontaram associação significativa quanto ao preço das ações, tanto de empresas de alta quanto de baixa tecnologia. No entanto, observou-se uma adoção estratégica quanto ao reconhecimento dos gastos com $\mathrm{P} \& \mathrm{D}$, os quais podem ser lançados como despesa ou investimento, levando-se em conta a intensidade tecnológica da organização. Todas as empresas de alta tecnologia realizaram o reconhecimento contábil em investimento e quase a totalidade das empresas de baixa tecnologia, em despesas. A opção de reconhecimento adotada pelas empresas de alta tecnologia é tática, uma vez que remete a expectativas de ganhos futuros.

Pires et al (2015) investigaram o impacto que o investimento em P\&D provoca no faturamento empresarial. Tal estudo apresentou uma relação expressiva entre as variáveis analisadas, ao encontrar que mais de $60 \%$ da elevação do faturamento decorre dos investimentos realizados em P\&D. Outra correlação apresentada é a existente entre o investimento em P\&D e a quantidade de pessoas dentro da empresa envolvidas nesse processo, bem como o estudo evidenciou que as empresas precisam investir em melhorias contínuas para se adequarem às exigências do mercado.

A influência que a P\&D exerce no desempenho de empresas foi objeto de estudo de Camargo, Zanin, Diel e Bianchet(2016) por meio da análise de rentabilidade (ROA) em empresas do bloco econômico G20. Os dados demonstraram que o investimento em P\&D reflete negativamente no ROA. Apesar disso, os autores consideram que a P\&D beneficia as organizações ao longo do tempo, e que o mercado, vagarosamente, capta a amplitude desses benefícios.

A relação entre o investimento em P\&D e o crescimento das vendas, ponderando-se diferentes níveis de proximidade com a fronteira tecnológica, motivou o estudos de Rocha, Dal-Poz, Oliveira e Almeida (2016). O resultado apontou que o investimento, ao produzir inovação, contribui de forma significativa para o aumento das vendas, sendo esse fator mais perceptível em em- 
presas com nível tecnológico avançado, nas quais um aumento de $1 \%$ do investimento em P\&D resulta em ascensão nas vendas de $0,40 \%$, ao passo que, em empresas com grau inferior de tecnologia, o aumento das vendas é de apenas $0,16 \%$ para uma elevação de $1 \%$ no investimento em P\&D.

Figueiredo, Barros e Conceição (2012) pesquisaram na citricultura paulista a mensuração dos retornos econômicos decorrentes do investimento em P\&D por meio da análise do crescimento da produtividade total dos fatores (PTF). Como resultado, foi detectado que o investimento em $P \& D$ tem relevância para o setor, ao ser verificado um retorno de $R \$ 13,67$ para cada $R \$ 1,00$ investido.

Por sua vez, Schmidt e Silva (2018) estudaram a dinâmica da Pesquisa e Desenvolvimento na cadeia produtiva de frangos de corte no Brasil, desde a produção até a industrialização. Os resultados apresentaram que a existência de estrutura própria para o investimento em $P \& D$, em busca de apresentar produtos e processos novos, é preponderante nas empresas que compõem essa cadeia de produção. Outro fator destacado são as parcerias realizadas por essas organizações, sobretudo com instituições públicas, como universidades e institutos.

O trabalho de Espíndola et al (2018) buscou analisar a relevância em divulgar os gastos em P\&D no mercado de capitais brasileiro. Os dados revelaram o pouco comprometimento das empresas em efetuar gastos com inovação por meio de $\mathrm{P} \& \mathrm{D}$, e que os gastos realizados nessa atividade não impacta de maneira informacional no valor das entidades, ou seja, a difusão dos dispêndios praticados por essas empresas em P\&D não incrementam o seu valor de mercado.

Chan et al (2001) consideram que a P\&D se associa ao preço das ações a partir da percepção dos investidores em admitir que ativos intangíveis, tais como pesquisa e desenvolvimento agregam valor à entidade. Discordante desse fato, o estudo de Hungarato e Teixeira (2012) não obteve resultado que tenha demonstrado associação significativa entre preço das ações e gastos com P\&D. A presente pesquisa se diferencia do estudo de Hungarato e Teixeira (2012) por analisar apenas o setor de energia elétrica, enquanto os referidos autores analisaram todas as empresas listadas na Bovespa. Além disso, o período de verificação é diferente, bem como o modelo utilizado. Nesta pesquisa, foram inseridas as variáveis tamanho da empresa (TA), fluxo de caixa operacional (FCO) e o risco sistemático, composto pela liquidez corrente (LC) e o risco de solvência (RIS), as quais não estiveram presentes no trabalho de Hungarato e Teixeira (2012).

Apesar de diversos estudos terem sido realizados sobre a associação da P\&D com outras variáveis, inclusive levando-se em conta o preço das ações, percebe-se que não há consenso nos resultados obtidos. Espíndola et al (2018) citam como possíveis causas para a desconformidade desses resultados fatores relacionados ao próprio ambiente analisado, como, por exemplo, um mercado em que a inovação não é incentivada e os investidores não consideram relevantes atividades relacionadas à inovação, como a $\mathrm{P} \& \mathrm{D}$, inferindo-se a essas atividades apenas os riscos econômicos e custos do investimento. Os autores opinam ainda que há lacunas a preencher na literatura em razão desse tipo de pesquisa que aponta que a relevância informacional de itens contábeis relacionados à inovação é menos comum em mercados emergentes.

Portanto, em razão da falta de consenso nos resultados de estudos anteriores e da escassez das pesquisas de value relevance que se baseiam em gastos com P\&D em mercados emergentes, este estudo busca contribuir com a literatura acerca da temática. Assim, considerando que os resultados dos estudos supracitados sugerem que maiores gastos em $P \& D$ estão relacionados à maior desempenho da empresa (Andreassi \& Sbragia, 2002; Pires et al, 2015), que investidores consideram que ativos intangíveis agregam valor à entidade (Chan et al., 1999), e considerando ainda que maiores gastos com pesquisa e desenvolvimento podem ser interpretados por investidores como maior potencial inovador e ver nisso vantagens competitivas sustentáveis perante à concorrência (Espíndola et al., 2018), formulou-se a seguinte hipótese: 
H1: Os gastos em P\&D apresentam associação positiva com o retorno das ações.

\section{PROCEDIMENTOS METODOLÓGICOS}

Com o objetivo de investigar se a realização do investimento em $\mathrm{P} \& \mathrm{D}$ agrega valor à entidade, esta pesquisa contempla o período de 2011 a 2018, sendo usada essa janela temporal em virtude de a atividade de P\&D ser uma ação voltada para o longo prazo (Andreassi \& Sbragia, 2002).

Os dados foram coletados na Base Economática ${ }^{\circledR}$, com exceção dos gastos com $\mathrm{P \& D}$, os quais foram coletados no site da B3 por meio da análise das notas explicativas das entidades. A análise é realizada por meio de regressão múltipla com dados em painel com o auxílio do software Stata13.

A população é composta por 47 empresas do setor de energia elétrica conforme classificação da Base Economática. A partir da população, foram eliminadas as empresas que estavam na base Economática ${ }^{\circledR}$ mas não estavam listadas na B3. Tal seleção ocorreu em virtude da necessidade de acesso às notas explicativas que são disponibilizadas no site da B3. Em seguida, foram excluídas as empresas que não apresentaram gastos com P\&D. Assim, a amostra foi definida, sendo representada por 23 companhias abertas do segmento de energia elétrica listadas na B3 - Brasil, Bolsa, Balcão, conforme disposto na Tabela 1.

Tabela 1 - Amostra de pesquisa

\begin{tabular}{lc}
\hline \multicolumn{1}{c}{ Critérios de definição amostral } & Empresas \\
\hline População (empresas da Base Economática) & 47 \\
\hline (-) Empresas não listadas na B3 & $(10)$ \\
\hline (-) Empresas sem gastos com P\&D & $(14)$ \\
\hline Total & 23 \\
\hline
\end{tabular}

Fonte: Elaborado pelos autores

O modelo estatístico utilizado é adaptado de Hungarato e Teixeira (2012) (Equação 1).

$$
\mathrm{RA}_{i \mathrm{t}}=\beta_{0}+\beta_{1 \mathrm{it}} \mathrm{PDD}_{1 \mathrm{it}}+\beta_{2 \mathrm{it}} \mathrm{LLPA} \mathrm{A}_{2 \mathrm{it}}+\beta_{3 \mathrm{it}} \mathrm{PLPA}_{3 \mathrm{it}}+\beta_{4 \mathrm{i}} \mathrm{TA}_{\mathrm{it}}+\beta_{5 \mathrm{i}} \mathrm{FCO}_{\mathrm{it}}+\beta_{6 \mathrm{i}} \mathrm{LC}_{\mathrm{it}}+\beta_{7 \mathrm{i}} \mathrm{RIS}_{\mathrm{it}}+\varepsilon_{i t}(1)
$$

Onde, it: representa a empresa $i$ no ano $t$ (ano corrente); RA: representa o retorno das ações; LLPA: representa o lucro líquido por ação líquido da despesa com P\&D; PLPA: representa o patrimônio líquido por ação líquido da despesa com P\&D; PDD: representa a despesa com P\&D; TA: representa o tamanho da empresa; FCO: representa o fluxo de caixa operacional; LC: representa a liquidez corrente; RIS: representa o risco de solvência; $\varepsilon_{\text {it: }}$ Termo do erro da regressão.

O retorno da ação é calculado pela diferença entre o preço de fechamento da ação no ano $t$ (ano corrente) e o preço de fechamento da ação no ano t-1 (ano anterior ao ano corrente) ponderado pelo preço de fechamento da ação no ano t-1. Considerando que os gastos com P\&D se tratam de uma ação voltada para o longo prazo (Andreassi \& Sbragia, 2002), os testes de regressão são realizados com as variáveis explicativas nos anos $t, t-1$ e $t-2$.

A adição das variáveis de controle é justificada de acordo com Rodrigues et al (2015), os quais afirmam que elas são relevantes para se determinar o valor de mercado das entidades. No Quadro 1, apresentam-se o cálculo das variáveis de controle, o sinal esperado entre sua relação com o retorno das ações e os embasamentos teóricos sobre essa relação. 
Quadro 1 - Determinantes do retorno das ações

\begin{tabular}{|c|c|c|c|}
\hline Variáveis & Fórmula & $\begin{array}{c}\text { Sinal } \\
\text { Espera- } \\
\text { do }\end{array}$ & Explicação da associação esperada \\
\hline PDD & $\frac{\text { Gastos com P\&D }}{\text { Ativo total it-1 }}$ & + & \\
\hline LLPA & LLPA - PDD & + & \multirow{2}{*}{$\begin{array}{l}\text { Assim como em Hungarato e Teixeira (2012), espe- } \\
\text { ra-se uma associação positiva entre as variáveis de } \\
\text { controle e o preço das ações. }\end{array}$} \\
\hline PLPA & PL por ação - PDD & + & \\
\hline TA & $\operatorname{LnAT}_{\mathrm{i}, \mathrm{t}}$ & + & $\begin{array}{l}\text { Empresas maiores estão mais propensas a realizar } \\
\text { investimento em P\&D devido ao interesse de seus } \\
\text { gestores em apresentar resultados que melhorem a } \\
\text { posição financeira da entidade e para benefício } \\
\text { próprio, visto que sua remuneração é baseada no } \\
\text { preço das ações. Essa atitude adotada por eles é } \\
\text { considerada uma aposta de risco Landry e Calli- } \\
\text { maci (2003). }\end{array}$ \\
\hline FCO & $\frac{\text { Fluxo de caixa das operações }}{\text { Ativo total it-1 }}$ & - & $\begin{array}{l}\text { Landry e Callimaci (2003) consideram que o grau } \\
\text { de fundos produzidos internamente é utilizado } \\
\text { para mensuração da atividade de P\&D das enti- } \\
\text { dades, visto que a maior parte das empresas prio- } \\
\text { rizam a realização desses investimentos por meio } \\
\text { do financiamento interno. }\end{array}$ \\
\hline $\mathrm{LC}$ & $\begin{aligned} \text { Liquidez Corrente } & =\underline{\text { Ativo Circulante }} \\
& \text { Passivo Circulante }\end{aligned}$ & + & \multirow{2}{*}{$\begin{array}{l}\text { Os fatores de risco, segundo Ariff, Fah e Ni (2013), } \\
\text { são o risco de liquidez (LC) e o risco de solvência } \\
\text { (RIS). As variações desses índices provocam alte- } \\
\text { rações no preço das ações. Esses riscos impactam } \\
\text { no preço das ações, pois são fatores que podem } \\
\text { ocasionar desequilíbrios nas instituições, sendo, } \\
\text { portanto, uma informação relevante para os usuá- } \\
\text { rios da informação, principalmente, os investido- } \\
\text { res (Goulart \& Carvalho, 2004). }\end{array}$} \\
\hline RIS & Risco de solvência $=\frac{\text { Patrimônio líquido }}{\text { Ativo total it-1 }}$ & + & \\
\hline
\end{tabular}

Nota: PDD: representa a despesa com P\&D; LLPA: representa o lucro líquido por ação líquido da despesa com P\&D; PLPA: representa o patrimônio líquido por ação líquido da despesa com P\&D; TA: tamanho da empresa; FCO: fluxo de caixa operacional; LC: liquidez corrente; RIS: risco de solvência.

Fonte: Elaborado pelos autores.

Após efetuar todos os cálculos das variáveis, foi realizado o procedimento de winsorização ao nível de 5\%, cujo intuito é mitigar o efeito dos outilers nas inferências dos resultados. Na Tabela 2, são exibidos os testes dos pressupostos de heterocedasticidade, normalidade e multicolinearidade dos resíduos.

Tabela 2 - Diagnósticos do modelo

\begin{tabular}{lcrrrr}
\hline \multirow{2}{*}{ Teste } & Normalidade & Multicolinearidade & \multicolumn{2}{c}{ Heterocedasticidade } \\
\cline { 2 - 6 } & \multicolumn{2}{c}{ SWilk } & VIF & Breusch-Pagan & White \\
\cline { 2 - 6 } & \multicolumn{2}{c}{ Prob $>\mathrm{Z}$} & Média VIF & Prob $>$ chi2 & Prob $>$ chi2 \\
\hline Variáveis explicativas no ano $\mathbf{t}$ & 0,001 & 1,640 & 0,417 & 0,494 \\
\hline Variáveis explicativas no ano t-1 & 0,000 & 1,650 & 0,000 & 0,018 \\
\hline Variáveis explicativas no ano t-2 & 0,009 & 1,630 & 0,000 & 0,005 \\
\hline
\end{tabular}

Fonte: Dados da pesquisa. 
A inexistência de heterocedasticidade foi constatada no teste de Breusch-Pagan para os modelos com as variáveis, isto é, as variâncias dos erros são iguais e os resíduos são homoscedásticos. O teste Shapiro-Wilk, evidencia que os resíduos das regressões não retrataram disposição normal ao nível de significância de 5\%. O teste Variance Inflation Factor (VIF) apresenta valores inferiores a 3, insinuando a inexistência de multicolinearidade abrangendo todas as variáveis do modelo. A estimação dos modelos por erros padrões robustos foi realizada, aspirando minimizar problemas decorrentes da homoscedasticidade e anormalidade dos resíduos.

Com o objetivo de verificar a existência de endogeneidade entre as variáveis foram realizados os testes de especificação ovtest e ivreg. Os resultados apontam não haver problemas de variáveis omitidas, sendo os regressores não endógenos. Assim, os modelos adotados neste estudo foram estimados pelo método de Mínimos Quadrados Ordinários (MQO) com a assistência do Software Stata. Os resultados em relação ao método de estimação apropriado para cada modelo são apresentados na Tabela 3.

Tabela 3 - Método de estimação

\begin{tabular}{|c|c|c|c|c|c|c|c|}
\hline \multirow[t]{2}{*}{ Teste } & \multicolumn{2}{|c|}{ Chow } & \multicolumn{2}{|c|}{ Hausman } & \multicolumn{2}{|c|}{ Breusch-Pagan } & \multirow{2}{*}{$\begin{array}{l}\text { Método de } \\
\text { estimação } \\
\text { adequado }\end{array}$} \\
\hline & $\mathrm{F}$ & Prob $>$ F & Chi2 & Prob>chi2 & Chi2 & $\begin{array}{l}\text { Prob }> \\
\text { chibar2 }\end{array}$ & \\
\hline $\begin{array}{l}\text { Variáveis } \\
\text { explicativas } \\
\text { no ano } t\end{array}$ & 1,250 & 0,223 & 18,450 & 0,010 & 0,000 & 1,000 & Pooled \\
\hline $\begin{array}{l}\text { Variáveis } \\
\text { explicativas } \\
\text { no ano t-1 }\end{array}$ & 1,380 & 0,144 & 17,460 & 0,015 & 3,200 & 0,037 & $\begin{array}{c}\text { Efeito Aleató- } \\
\text { rio }\end{array}$ \\
\hline $\begin{array}{l}\text { Variáveis } \\
\text { explicativas } \\
\text { no ano t-2 }\end{array}$ & 0,860 & 0,643 & 9,280 & 0,233 & 0,000 & 1,000 & Pooled \\
\hline
\end{tabular}

Fonte: Dados da pesquisa.

Os testes de Chow, Hausman e Breusch-Pagan foram realizados com o intuito de verificar qual é o método de estimação mais adequado para cada modelo. Os resultados apontam que para o modelo com as variáveis explicativas nos anos $t$, e $t-2$, os estimadores do modelo restrito são sólidos. Já no modelo com as variáveis no ano t-1 a estimação pelo efeito aleatório é a mais adequada.

\section{APRESENTAÇÃO E ANÁlISE DOS RESULTADOS}

Na Tabela 4 é exposta a estatística descritiva das variáveis aplicadas no modelo. A média da variável RA resulta em 0,13 , sendo esse um valor inferior ao encontrado por Hungarato e Teixeira (2012), que foi de 1,422. No entanto, vale ressaltar que esses autores analisaram todas as empresas brasileiras listadas na Bovespa, enquanto este estudo se limita a investigar apenas o setor de energia elétrica. Em relação ao LLPA e o PLPA, ocorreu o inverso na pesquisa de Hungarato e Teixeira (2012), visto que a média da variável foi de 0,289 e 2,441, respectivamente, enquanto, no presente estudo, foram encontradas as médias de 1,67 e 17,547, respectivamente.

Em relação às variáveis FCO e TA, as médias obtidas foram de 0,086 para a primeira e 15,878, para a segunda. Esses valores diferem das médias encontradas no trabalho de Gonçalves e Lemes (2018), o qual verificou uma média de 15,35543 para o FCO e 1,473055, para o TA. No entanto, esse autor pesquisou apenas empresas brasileiras de capital aberto de média e alta tecnologia, portanto uma amostra com características diferentes das utilizadas neste estudo. Quanto à liquidez corrente (LC) e risco de solvência (RIS), as médias foram de 1,271 e 0,401, respectivamente. 
Tabela 4 - Estatística descritiva

\begin{tabular}{ccrrrrr}
\hline Variável & $\begin{array}{c}\text { Número de } \\
\text { observações }\end{array}$ & \multicolumn{1}{l}{ Média } & Desvio padrão & Mínimo & Máximo & P50 \\
\hline RA & 160 & 0,130 & 0,333 & $-0,362$ & 0,929 & 0,078 \\
\hline PDD & 160 & 0,004 & 0,002 & 0,001 & 0,009 & 0,004 \\
\hline LLPA & 160 & 1,671 & 1,730 & $-1,106$ & 5,246 & 1,401 \\
\hline PLPA & 160 & 17,547 & 14,826 & 1,260 & 54,314 & 14,754 \\
\hline TA & 160 & 15,878 & 1,008 & 13,909 & 17,518 & 15,988 \\
\hline FCO & 160 & 0,086 & 0,060 & $-0,011$ & 0,205 & 0,077 \\
\hline LC & 160 & 1,271 & 0,618 & 0,646 & 3,047 & 1,111 \\
\hline RIS & 160 & 0,401 & 0,141 & 0,196 & 0,698 & 0,382 \\
\hline
\end{tabular}

Nota: RA: representa o retorno da ação; PDD: representa a despesa com P\&D; LLPA: representa o lucro líquido por ação líquido da despesa com P\&D; PLPA: representa o patrimônio líquido por ação líquido da despesa com P\&D; TA: tamanho da empresa; FCO: fluxo de caixa operacional; LC: liquidez corrente; RIS: risco de solvência.

Fonte: Dados da pesquisa.

A Tabela 5 retrata os resultados da correlação de Spearman entre as variáveis do estudo. Os resultados demonstram que o investimento em $\mathrm{P} \& \mathrm{D}$ e o retorno das ações não estão correlacionados, o que sugere que o investimento em P\&D não afeta o retorno das ações. A única variável do modelo que apresenta correlação com o retorno das ações é a liquidez corrente (LC), o que sugere que, quanto mais elevado fora capacidade da empresa em honrar as dívidas de curto prazo, maior será o retorno das ações. Portanto, em princípio, presume-se que as variáveis de controle podem exercer pouca ou nenhuma influência no retorno das ações. Entretanto os testes econométricos são realizados com o objetivo de relatar a relação entre as variáveis de controle e dependente.

Tabela 5 - Matriz de correlação de Spearman

\begin{tabular}{|c|c|c|c|c|c|c|c|c|}
\hline & RA & PDD & LLPA & PLPA & TA & FCO & LC & RIS \\
\hline \multirow[t]{2}{*}{ RA } & 1 & & & & & & & \\
\hline & 0,000 & & & & & & & \\
\hline \multirow[t]{2}{*}{ PDD } & 0,009 & 1,0000 & & & & & & \\
\hline & 0,914 & 0,000 & & & & & & \\
\hline \multirow[t]{2}{*}{ LLPA } & 0,042 & 0,099 & 1,0000 & & & & & \\
\hline & 0,596 & 0,215 & 0,000 & & & & & \\
\hline \multirow[t]{2}{*}{ PLPA } & $-0,118$ & 0,149 & 0,442 & 1,0000 & & & & \\
\hline & 0,136 & 0,060 & 0,000 & 0,000 & & & & \\
\hline \multirow[t]{2}{*}{ TA } & 0,063 & $-0,104$ & 0,032 & $-0,016$ & 1,0000 & & & \\
\hline & 0,429 & 0,191 & 0,690 & 0,839 & 0,000 & & & \\
\hline \multirow[t]{2}{*}{ FCO } & 0,080 & 0,069 & 0,118 & $-0,225$ & $-0,145$ & 1,0000 & & \\
\hline & 0,315 & 0,388 & 0,137 & 0,004 & 0,067 & 0,000 & & \\
\hline \multirow[t]{2}{*}{ LC } & 0,148 & $-0,017$ & 0,004 & $-0,286$ & $-0,145$ & 0,104 & 1,0000 & \\
\hline & 0,063 & 0,834 & 0,963 & 0,000 & 0,068 & 0,191 & 0,000 & \\
\hline \multirow[t]{2}{*}{ RIS } & $-0,085$ & $-0,195$ & 0,278 & 0,304 & $-0,316$ & 0,296 & 0,295 & 1 \\
\hline & 0,285 & 0,013 & 0,000 & 0,000 & 0,000 & 0,000 & 0,000 & 0,000 \\
\hline
\end{tabular}

Nota: RA: representa o retorno da ação; PDD: representa a despesa com P\&D; LLPA: representa o lucro líquido por ação líquido da despesa com P\&D; PLPA: representa o patrimônio líquido por ação líquido da despesa com P\&D; TA: tamanho da empresa; FCO: fluxo de caixa operacional; LC: liquidez corrente; RIS: risco de solvência.

Fonte: Dados da pesquisa.

Na Tabela 6 estão expostos os resultados da regressão do modelo com a técnica MQO para os anos $t$, $t$-1 e $t$-2. Os achados demonstram que não há significância entre a relação do retorno das ações com os gastos em pesquisas e desenvolvimento das empresas nos anos t e t-1. Porém, há relação positiva e significante no ano t-2 com coeficiente de 33,440 e p-valor de 0,039. Isso sugere que os gastos com pesquisa e desenvolvimento realizados pelas empresas demoram pelo menos 3 anos 
para surtir efeito sobre o retorno das ações. Justifica-se tal resultado considerando que os gastos com pesquisa e desenvolvimento se referem a uma questão de longo prazo, ou seja, não afetam de imediato o resultado da empresa, levando algum tempo para gerar resultados positivos e retorno. De acordo com Gonçalves, Conegliam e Carmo (2017), os investimentos em P\&D reconhecidos como ativo é uma informação considerada relevante para o mercado de capitais, ao passo que o reconhecimento como despesa afeta negativamente a relevância da informação, o que pode ajudar a explicar a insignificância da $P \& D$, nos anos t e t-1, para as companhias elétricas em virtude de essas entidades serem obrigadas a reconhecer o gasto com a pesquisa e o desenvolvimento como despesa.

Tais achados se destoam do que foi encontrado por Hungarato e Teixeira (2012), ao analisarem as empresas listadas na Bovespa, e por Alves et al (2011), ao pesquisarem o mesmo setor objeto deste estudo, ou seja, o setor de energia elétrica. Talvez uma explicação para isso seja a diferença temporal entre as referidas pesquisas, e ainda o fato de tais estudos terem utilizado o preço das ações e não o retorno das ações, conforme a presente pesquisa. Hungarato e Teixeira (2012) e Alves et al (2011) buscam justificar seus achados destacando que dentre os fatores que motivam a irrelevância dos investimentos com P\&D para o mercado de capitais encontra-se a legislação à qual o setor está submetido, e que gera a obrigatoriedade desse investimento, sendo esse o elemento que configura a P\&D como um diferencial atraente aos investidores.

Tabela 6 - Regressão MQO

\begin{tabular}{|c|c|c|c|c|c|}
\hline Variáveis explicativas & $\begin{array}{c}\text { Sinal } \\
\text { previsto }\end{array}$ & & Ano t & Ano t-1 & Ano t-2 \\
\hline \multirow[t]{3}{*}{ PDD } & \multirow[t]{3}{*}{+} & beta & $-5,483$ & 15,178 & 33,440 \\
\hline & & estatística t & $-0,450$ & 0,920 & 2,090 \\
\hline & & $\mathrm{p}$-valor & 0,657 & 0,357 & 0,039 \\
\hline \multirow[t]{3}{*}{ LLPA } & \multirow[t]{3}{*}{+} & beta & 0,022 & 0,006 & $-0,018$ \\
\hline & & estatística t & 1,080 & 0,240 & $-0,750$ \\
\hline & & p-valor & 0,282 & 0,810 & 0,456 \\
\hline \multirow[t]{3}{*}{ PLPA } & \multirow[t]{3}{*}{+} & beta & 0,000 & $-0,004$ & $-0,004$ \\
\hline & & estatística t & $-0,140$ & $-1,320$ & $-0,900$ \\
\hline & & p-valor & 0,886 & 0,186 & 0,369 \\
\hline \multirow[t]{3}{*}{ TA } & \multirow[t]{3}{*}{+} & beta & 0,006 & $-0,005$ & 0,016 \\
\hline & & estatística t & 0,200 & $-0,140$ & 0,440 \\
\hline & & p-valor & 0,842 & 0,885 & 0,661 \\
\hline \multirow[t]{3}{*}{ FCO } & \multirow[t]{3}{*}{+} & beta & 0,354 & $-1,594$ & $-1,597$ \\
\hline & & estatística t & 0,640 & $-2,610$ & $-2,130$ \\
\hline & & p-valor & 0,520 & 0,009 & 0,036 \\
\hline \multirow[t]{3}{*}{ LC } & \multirow[t]{3}{*}{+} & beta & 0,125 & 0,025 & 0,104 \\
\hline & & estatística $t$ & 2,070 & 0,510 & 1,260 \\
\hline & & $\mathrm{p}$-valor & 0,040 & 0,611 & 0,211 \\
\hline \multirow[t]{3}{*}{ RIS } & \multirow[t]{3}{*}{+} & beta & $-0,600$ & 0,002 & $-0,005$ \\
\hline & & estatística $t$ & $-2,080$ & 0,010 & $-0,010$ \\
\hline & & p-valor & 0,039 & 0,994 & 0,991 \\
\hline \multirow[t]{3}{*}{ Constante } & \multirow[t]{3}{*}{$?$} & beta & 0,075 & 0,316 & $-0,135$ \\
\hline & & estatística $t$ & 0,130 & 0,420 & $-0,210$ \\
\hline & & $\mathrm{p}$-valor & 0,898 & 0,674 & 0,836 \\
\hline R-squarewhithin & & & 0,063 & 0,051 & 0,156 \\
\hline R-squarebetween & & & - & 0,289 & - \\
\hline$R$-square overall & & & - & 0,072 & - \\
\hline Prob $>$ F & & & - & 0,030 & - \\
\hline Número observações & & & 160 & 140 & 120 \\
\hline Número de grupos & & & - & 22 & - \\
\hline
\end{tabular}


Nota: RA: representa o retorno da ação; PDD: representa a despesa com P\&D; LLPA: representa o lucro líquido por ação líquido da despesa com P\&D; PLPA: representa o patrimônio líquido por ação líquido da despesa com P\&D; TA: tamanho da empresa; FCO: fluxo de caixa operacional; LC: liquidez corrente; RIS: risco de solvência.

Fonte: Dados da pesquisa.

Quanto às demais variáveis de controle, o lucro líquido por ação (LLPA) e o patrimônio líquido por ação (PLPA) mostraram ser não significantes para o valor de mercado das ações em todos os períodos analisados. Esses resultados corroboram os estudos de Alves et al (2011) na análise do setor de energia elétrica, os quais demonstram que no modelo de regressão com as variáveis LLPA, PLPA e a PDD em conjunto, foi constatado que não ocorre relevância para interferência no retorno das ações. Porém, ainda nos estudos de Alves et al (2011), as variáveis LLPA e PLPA são significantes para o mercado de capitais do Brasil quando analisadas isoladamente.

A variável tamanho da empresa (TA) mostrou não ser significativa e com associação positiva para os anos $t, t-1$ e $t$-2, o que contraria os resultados do estudo de Rodrigues et al (2015). Os fatores que tornam essa variável importante para mensurar o retorno das ações são apontados por Landry e Callimaci (2003), que atribuem à gestão das grandes companhias o interesse em investir em $P \& D$, considerando-a uma atividade de risco com o fim de obter maiores ganhos oriundos do aumento do retorno das ações. A possibilidade de ganho pela valorização das ações está relacionada à expectativa de que o investimento na $\mathrm{P} \& \mathrm{D}$, atividade de risco, resulte em um projeto lucrativo para a organização (Chan et al, 2001).

A variável fluxo de caixa operacional (FCO) apresentou significância para justificar o retorno das ações nos anos t-1 e t-2, sendo não significante para o ano t. Landry e Callimaci (2003) fundamentam que o FCO é um fator considerado pelos investidores ao se analisar a atividade de P\&D de uma entidade, pois esses optam por empresas que tenham fluxos disponíveis para esse investimento sem a necessidade de financiamento externo, em razão da dificuldade de obtenção desse aporte.

O Risco Sistemático, composto pelo risco de liquidez corrente (LC) e risco de solvência (RIS), demonstrou ser significante para fundamentar o retorno das ações apenas no ano t. Ariff et al (2013) opinam que o risco sistemático influencia positivamente o retorno das ações, pois quando esses índices apresentam valores elevados, ocorre diminuição dos riscos de mercado e acréscimo nos retorno das ações. Os autores ainda consideram que esses riscos se mostram relevantes para mercados nos quais há maior desconfiança nas instituições por parte dos investidores.

\subsection{Análise adicional}

Com o objetivo de verificar a robustez e sensibilidade dos resultados, a regressão também foi estimada pelo método dos momentos generalizados (GMM). Destaca-se que os achados são robustos quanto à análise dos anos t e t-1, onde a variável pesquisa e desenvolvimento não apresentam relação significante com o retorno das ações, assim como documentado nos testes que envolvem a regressão estimada pela técnica MQO. Quanto ao ano t-2, diferente da técnica MQO, a qual sugere que a PDD tem relação positiva com o retorno das ações, na técnica GMM os resultados não são significantes. 
Tabela 6 - Regressão GMM

\begin{tabular}{|c|c|c|c|c|c|}
\hline $\begin{array}{c}\text { Variáveis explicati- } \\
\text { vas }\end{array}$ & Sinal previsto & & Ano $t$ & Ano t-1 & Ano t-2 \\
\hline \multirow{3}{*}{ PDD } & \multirow{3}{*}{+} & beta & $-36,326$ & $-19,930$ & $-14,886$ \\
\hline & & estatística $\mathrm{z}$ & $-0,930$ & $-0,440$ & $-0,350$ \\
\hline & & p-valor & 0,354 & 0,663 & 0,730 \\
\hline \multirow{3}{*}{ LLPA } & \multirow{3}{*}{+} & beta & $-0,006$ & 0,008 & 0,055 \\
\hline & & estatística z & $-0,300$ & 0,210 & 2,190 \\
\hline & & p-valor & 0,761 & 0,837 & 0,029 \\
\hline \multirow{3}{*}{ PLPA } & \multirow{3}{*}{+} & beta & $-0,013$ & 0,021 & $-0,057$ \\
\hline & & estatística $\mathrm{z}$ & $-1,500$ & 0,960 & $-2,950$ \\
\hline & & p-valor & 0,133 & 0,338 & 0,003 \\
\hline \multirow{3}{*}{ TA } & \multirow{3}{*}{+} & beta & 0,484 & 0,567 & 0,637 \\
\hline & & estatística z & 3,210 & 2,830 & 2,740 \\
\hline & & p-valor & 0,001 & 0,005 & 0,006 \\
\hline \multirow{3}{*}{ FCO } & \multirow{3}{*}{+} & beta & 1,752 & $-0,446$ & $-2,665$ \\
\hline & & estatística $\mathrm{z}$ & 2,950 & $-0,490$ & $-2,810$ \\
\hline & & p-valor & 0,003 & 0,627 & 0,005 \\
\hline \multirow{3}{*}{ LC } & \multirow{3}{*}{-} & beta & 0,100 & $-0,130$ & $-0,063$ \\
\hline & & estatística $\mathrm{z}$ & 1,030 & $-1,240$ & $-0,460$ \\
\hline & & $\mathrm{p}$-valor & 0,304 & 0,216 & 0,643 \\
\hline \multirow{3}{*}{ RIS } & \multirow{3}{*}{+} & beta & $-0,579$ & $-0,166$ & 0,495 \\
\hline & & estatística z & $-0,980$ & $-0,250$ & 0,770 \\
\hline & & p-valor & 0,328 & 0,804 & 0,440 \\
\hline \multirow{3}{*}{ Constante } & \multirow{3}{*}{$?$} & beta & $-7,246$ & $-8,900$ & $-8,849$ \\
\hline & & estatística $\mathrm{z}$ & $-3,060$ & $-2,860$ & $-2,580$ \\
\hline & & p-valor & 0,002 & 0,004 & 0,010 \\
\hline \multicolumn{3}{|l|}{ Prob > chi2 } & 0,000 & 0,002 & 0,000 \\
\hline \multicolumn{3}{|l|}{ Número observações } & 114 & 94 & 75 \\
\hline \multicolumn{3}{|l|}{ Número de grupos } & 21 & 20 & 19 \\
\hline
\end{tabular}

Nota: RA: representa o retorno da ação; PDD: representa a despesa com P\&D; LLPA: representa o lucro líquido por ação líquido da despesa com P\&D; PLPA: representa o patrimônio líquido por ação líquido da despesa com P\&D; TA: tamanho da empresa; FCO: fluxo de caixa operacional; LC: liquidez corrente; RIS: risco de solvência.

Fonte: Dados da pesquisa.

Em suma, os achados da presente pesquisa indicam que os gastos com pesquisa e desenvolvimento realizados pelas empresas demoram pelo menos 3 anos para surtir efeito sobre o retorno das ações, confirmando que os gastos com pesquisa e desenvolvimento se referem a uma questão de longo prazo, ou seja, não afetam de imediato o resultado da empresa, levando algum tempo para gerar resultados positivos e retorno.

\section{CONSIDERAÇÕES FINAIS}

Esta pesquisa teve como objetivo verificar se o investimento em Pesquisa \& Desenvolvimento promove value relevance para o mercado de capitais, ou seja, se existe associação entre esse investimento e o retorno das ações. A amostra da pesquisa foi delimitada e abrangeu as companhias de energia elétrica listadas na B3 - Brasil, Bolsa, Balcão, no período de 2011 a 2018.

Os principais resultados apontaram que o investimento em P\&D mostrou ser significante para explicar o retorno das ações, indicando que demoram pelo menos 3 anos para surtir efeito. Isso confirma que os gastos com pesquisa e desenvolvimento se referem a uma questão de longo prazo, e, portanto, não afetam de imediato o resultado da empresa. Assim, a presente pesquisa se destoa de estudos anteriores que buscaram evidenciar a relevância da P\&D para o mercado de capitais. $\mathrm{O}$ fato de haver controvérsias entre os resultados das pesquisas abre questionamentos para que análises ainda sejam realizadas à respeito do tema, especificamente sobre o tratamento 
que os investidores e o mercado dão a esse tipo de informação. Tratando-se do setor de energia elétrica, este estudo pode ajudar tais empresas a verificar o reflexo da obrigatoriedade do investimento em P\&D nos resultados, especificamente no retorno das ações.

É interessante notar que, mesmo com a atenção e importância atribuída à $P \& D$, evidenciada pelo interesse das entidades em desenvolver produtos e processos otimizados, não há consenso sobre o reflexo no valor de mercado das empresas. Essa condição pode ser em decorrência da dificuldade que acomete os projetos de $\mathrm{P} \& \mathrm{D}$ ao realizar previsão de benefícios futuros. Essa incerteza está relacionada ao âmbito comercial e econômico, podendo gerar prejuízos à qualidade da informação divulgada, além de torná-la irrelevante para os investidores, por estar mais associada a um risco do que a uma vantagem futura (Gonçalves \& Lemes, 2018).

As principais contribuições da presente pesquisa são corroborar com estudos prévios à respeito do tema, no sentido de evidenciar que os gastos com P\&D podem refletir positivamente sobre o valor de mercado, mesmo que seja em longo prazo. Além disso, os resultados poderão ser de interesse de outras empresas ou setores da economia interessados em realizar investimento em $\mathrm{P} \& \mathrm{D}$, os quais poderão avaliar os possíveis benefícios de tal decisão antes de realizá-la. Assim, o presente estudo avança em termos científicos ao acrescentar a variável P\&D como relevante para explicar o retorno das ações das empresas do setor elétrico, bem como ampliar as discussões a respeito do tema antes realizadas por pesquisas prévias, por exemplo Alves et al (2011) e Hungarato e Teixeira (2012).

Este estudo tem como fator limitante as regras de legislação à qual o setor de energia elétrica está submetido. Assim sendo, como sugestão para estudos futuros, propõe-se a investigação em setores diferentes a fim de verificar se as características próprias dos setores interferem nos resultados ou mesmo se há setores que obtenham maiores vantagens em relação a outros ao promover gastos com P\&D.

\section{REFERÊNCIAS}

Alves, A. P., Silva, T. G., da Silva Macedo, M. A., \& da Costa Marques, J. A. V. (2011). A relevância dos gastos com P\&D para o mercado brasileiro de capitais: um estudo com distribuidoras de energia elétrica no período de 2002 a 2009. RAI Revista de Administração e Inovação, 8(2), 216-239.

Andreassi, T., \& Sbragia, R. (2002). Relações entre indicadores de P\&D e de resultado empresarial. Revista de Administração da Universidade de São Paulo, 37(1), 72-84.

Ariff, M., Fah, C. F., \& Ni, S. W. (2013). Earnings response coefficients of OECD banks: Tests extended to include bank risk factors. Advances in Accounting, 29(1), 97-107.

Barth, M. E., Beaver, W. H., \& Landsman, W. R. (2001). The relevance of the value relevance literature for financial accounting standard setting: another view. Journal of accounting and economics, 31(1-3), 77-104.

Berto, A. M., \& Junior, C. M. D. (2015). Investimentos em P\&D (Pesquisa \& Desenvolvimento) e potenciais reflexos nos custos de produção. In Congresso Brasileiro de Engenharia de Produção, $V$.

BRASIL. Agência Nacional de Energia Elétrica. (2012). Manual do programa de pesquisa e desenvolvimento tecnológico do setor de energia elétrica. Brasília. http://www.aneel.gov.br/documents/656831/14943930/Manual+P\%26D+2012/eaef69f8-533143f8-b3ef-fab1c2775ed1. 
Calmanovici, C. E. (2011). A inovação, a competitividade e a projeção mundial das empresas brasileiras. Revista USP, (89), 190-203.

Camargo, T. F., Zanin, A., Diel, F. J., \& Bianchet, T. D. S. A. (2016). Influência da P\&D no desempenho de empresas: análise do bloco econômico G 20. In Anais do Congresso Brasileiro de Custos$A B C$.

Chan, S. H., Martin, J. D., \& Kensinger, J. W. (1990). Corporate research and development expenditures and share value. Journal of Financial Economics, 26(2), 255-276.

Chan, L. K., Lakonishok, J., \& Sougiannis, T. (2001). The stock market valuation of research and development expenditures. The Journal of Finance, 56(6), 2431-2456.

Comitê de Pronunciamentos Contábeis (2011). CPC 00. Estrutura Conceitual para elaboração e divulgação de relatório contábil-financeiro.

Espíndola, A., dos Santos, J. G. C., \& de Vasconcelos, A. C. (2018). Relevância informacional atribuída ao disclosure de gastos com P\&D no mercado de capitais brasileiro. Contextus: Revista Contemporânea de economia e gestão, 16(1), 115-140.

Ferrari, V. E. (2012). O padrão de financiamento dos investimentos produtivos e dos gastos com pesquisa e desenvolvimento das empresas brasileiras. Revista de Estudos Sociais, 14(27), 59-67.

Figueiredo, M. G. D., Barros, A. L. M. D., \& Conceição, J. C. P. R. D. (2012). Retorno econômico dos investimentos em P\&D na citricultura paulista. Revista de Economia e Sociologia Rural, 50(3), 493502.

Galdi, F. C., Teixeira, A. J. C., \& Lopes, A. B. (2008). Análise empírica de modelos de valuation no ambiente brasileiro: fluxo de caixa descontado versus modelo de Ohlson (RIV). Revista Contabilidade \& Finanças, 19(47), 31-43.

Gomes, R., Consoni, F. L., \& Galina, S. V. R. (2010). P\&D em filiais de empresas multinacionais instaladas no Brasil. Revista Pretexto, 11(1), 23-40.

Gonçalves, K. A., Conegliam, L., \& do Carmo, C. H. S. (2017). Value Relevance das Propriedades para Investimento: Evidência do Mercado de Capitais Brasileiro. Revista Contabilidade, Gestão e Governança, 20(1), 2-19.

Gonçalves, W. D. B., \& Lemes, S. (2018). A relação dos gastos com P\&D com a qualidade da informação contábil. Contabilidade Vista \& Revista, 29(2), 68-95.

GOULART, A.M.C. e CARVALHO, L.N. 2004. Evidenciação contábil do risco de mercado por instituições financeiras no Brasil. Journal of Accounting, Management and Governance, 7(1).

Hungarato, A., \& Teixeira, A. J. C. (2012). A Pesquisa e Desenvolvimento e os preços das ações das empresas brasileiras: um estudo empírico na Bovespa. Revista de Educação e Pesquisa em Contabilidade (REPeC), 6(3), 282-298. 
Jensen, J., Menezes-Filho, N., \& Sbragia, R. (2004). Os determinantes dos gastos em P\&D no Brasil: uma análise com dados em painel. Estudos Econômicos (São Paulo), 34(4), 661-691.

Landry, S., \& Callimaci, A. (2003). The effect of management incentives and cross-listing status on the accounting treatment of R\&D spending. Journal of International Accounting, Auditing and Taxation, 12(2), 131-152.

Lei no 9991, de 24 de julho de 2000. (2.000) Dispõe sobre realização de investimentos em pesquisa e desenvolvimento e em eficiência energética por parte das empresas concessionárias, permissionárias e autorizadas do setor de energia elétrica, e dá outras providências. Brasília, DF: Câmara dos Deputados.

Lima, M., \& Sauaia, A. (2008). Impacto dos Investimentos em P\&D nos Resultados Empresariais: um Estudo Laboratorial com Jogos de Empresas. Simpósio de Gestão da Inovação Tecnológica, 25.

Lo, K. (2010). Materiality and voluntary disclosures. Journal of Accounting and Economics, 49(1-2), 133-135.

Machado, M. A. V., da Silva Macedo, M. A., \& Machado, M. R. (2015). Análise da relevância do conteúdo informacional da DVA no mercado brasileiro de capitais. Revista Contabilidade $\mathcal{E}$ Finanças-USP, 26(67), 57-69.

Nez, E., Diel, F., \& Lavarda, C. E. F. (2016). Relação entre folga organizacional e P\&D nas companhias de energia elétrica na BM\&Fbovespa. REVISTA AMBIENTE CONTÁBIL-Universidade Federal do Rio Grande do Norte-ISSN 2176-9036, 8(1), 243-257.

OECD. (2015). Frascati Manual 2015: Guidelines for collecting and reporting data on research and experimental development. OECD Publishing.

Pires, D. B., Dalongaro, R. C., Júnior, R. R. S., \& Pires, D. B. (2015). Os Impactos no Faturamento Empresarial com os Investimentos em Pesquisa e Desenvolvimento. Revista GESTO, 3(1), 103111.

Queiroz, S. (2011). Obstáculos ao investimento em P\&D de empresas estrangeiras no Brasil. Revista USP, (89), 244-255.

Rocha, L. A., Dal-Poz, M. E., Oliveira, F. P. S. D., \& Almeida, C. A. S. D. (2016). O impacto dos investimentos em Pesquisa \& Desenvolvimento no desempenho das empresas. Revista de Economia Contemporânea, 20(1), 58-91.

Rodrigues, J. M., Elias, W. G., \& Campos, E. S. (2015). Relevância da Informação Contábil: uma análise dos efeitos da contabilização dos gastos com pesquisa e desenvolvimento com a aplicação da Lei 11.638/07 no mercado brasileiro. Revista Contabilidade e Controladoria, 7(3), 131-148.

Santos, M. S. D., \& Pinheiro, I. A. (2011). Governo: um aliado nem sempre lembrado pelas empresas na hora de desenvolver as atividades de P\&D. Rev. Adm. Pública, 45(3), 1465-1483. 
Schmidt, N. S., \& Silva, C. L. D. (2018). Pesquisa e desenvolvimento na cadeia produtiva de frangos de corte no Brasil. Revista de Economia e Sociologia Rural, 56(3), 467-482.

SILVA, M. C. (2015). Eficiência de mercado: qual o nível de value relevance das informações contábeis para as ações das empresas listadas na Bm\&FBovespa. Repositório Digital Institucional da UFPR. Curitiba.

Souza, M. M. D., \& Borba, J. A. (2017). Value relevance do nível de disclosure das combinações de negócios e do goodwill reconhecido nas companhias de capital aberto brasileiras. Revista Contabilidade \& Finanças, 28(73), 77-92.

Suadiye, G. (2012). Value relevance of book value \& earnings under the local GAAP and IFRS: Evidence from Turkey. Ege Akademik Bakış Dergisi, 12(3), 301-310. 